\title{
Experimental psycholinguistic approaches to second language acquisition
}

\section{Claudia Felser University of Essex}

While interest in issues relating to language processing has been a feature of second language acquisition (SLA) research for some time (see, for example, McLaughlin, 1987; VanPatten, 1996; Pienemann, 1998; Carroll, 2000), it is only comparatively recently that researchers have begun using experimental psycholinguistic methods to examine the way second language learners process the target language in real time. The aims of this thematic issue are to provide Second Language Research readers with a selective overview of current research in the area of second language (L2) processing, and to demonstrate how the use of on-line psycholinguistic methods can help advance our understanding of certain aspects of SLA.

The use of on-line techniques borrowed from the related disciplines of psychology or neuroscience provides SLA researchers with the opportunity to study aspects of L2 performance that are not otherwise open to direct observation (for overviews of on-line psycholinguistic methods suitable for SLA research see Juffs, 2001; Heredia and Stewart, 2002; Marinis, 2003). Specifically, the experimental psycholinguistic study of L2 processing may help provide answers to the following questions:

- What are the architectures, mechanisms and representations that underlie L2 processing, and how do they differ from those that underlie first language (L1) processing?

- To what extent are learners able to access and integrate different information sources when processing the L2 input? 
- What is the time-course of L2 processing, and how does it differ from that of L1 processing?

- Do learners transfer processing strategies from their native language to the L2?

- How do individual differences in L1 background, age of acquisition, L2 proficiency or working memory capacity influence L2 processing?

- Do L2 processing skills develop in conjunction with, or separately from, the L2 grammar?

The four contributions to this issue focus on three of the most commonly used on-line techniques in L2 processing research: self-paced reading (Papadopoulou, Juffs), event-related brain potentials (Mueller) and eye-tracking (Frenck-Mestre).

Papadopoulou's article provides an overview of reading-time studies that have investigated ambiguity resolution in the L2. Results from these studies suggest that while L2 learners-like native speakers-are sensitive to lexical-semantic information during L2 processing, even highly proficient learners do not necessarily process ambiguous sentences in a native-like fashion. Papadopoulou also addresses the issues of processing transfer and the role of exposure for L2 sentence processing, both of which, she argues, require further systematic investigation.

In his article, Juffs presents the results from a self-paced reading study on L2 learners' processing of wh-movement structures, comparing learners from different L1 backgrounds and investigating the possible influence of working memory differences on L2 processing. Juffs' findings that all learner groups show subject-object asymmetries in processing $w h$-extractions, and that learners have difficulty with subject extractions from finite but not from nonfinite clauses, lead him to revise Juffs \& Harrington's (1995) earlier hypothesis that the absence of overt $w h$-movement in the L1 may cause difficulties processing $w h$-subject extractions in the L2.

In her contribution, Mueller reviews the findings from studies that have used event-related brain potentials (ERPs) to investigate lexical, morphosyntactic and phonological processing in the L2. Results from these studies have revealed both similarities and differences between L1 and L2 processing. While lexical-semantic processing appears to be similar in the L1 and the L2, ERP components that are thought to reflect 
early automatic structure-building processes tend to be absent in late L2 learners. Mueller suggests that the extent to which L2 learners can develop native-like processing patterns may depend crucially on factors such as age of acquisition and L2 proficiency.

In the final contribution to this issue, Frenck-Mestre discusses the results from eye-tracking studies of L2 sentence processing, which, on the whole, point towards similarities rather than differences between L1 and L2 sentence processing. Frenck-Mestre shows how the eye-tracking method compares with the self-paced reading technique, on the one hand, and with ERPs on the other, and emphasizes the need for methodological diversity in the study of L2 processing.

Taken together, the articles in this special issue illustrate how SLA research might benefit from applying on-line methods familiar from the L1 processing literature to the study of L2 processing, and how findings from L2 processing studies might be interpreted in the context of existing psycholinguistic models of language processing.

\section{References}

Carroll, S. 2000: Input and evidence: the raw material of second language acquisition. Amsterdam: John Benjamins.

Heredia, R.R. and Stewart, M.T. 2002: On-line methods in bilingual spoken language research. In Heredia, R.R. and Altarriba, J., editors, Bilingual sentence processing, Amsterdam: Elsevier, 7-28.

Juffs, A. 2001: Psycholinguistically oriented second language research. Annual Review of Applied Linguistics 21, 207-20.

Juffs, A. and Harrington, M. 1995: Parsing effects in L2 sentence processing: subject and object asymmetries in wh-extraction. Studies in Second Language Acquisition 17, 483-516.

Marinis, T. 2003: Psycholinguistic techniques in second language acquisition research. Second Language Research 19, 144-61.

McLaughlin, B. 1987: Theories of second language learning. London: Edward Arnold.

Pienemann, M. 1998: Language processing and second language development: processability theory. Amsterdam: John Benjamins.

VanPatten, B. 1996: Input processing and grammar instruction in second language acquisition. Norwood, NJ: Ablex. 